\title{
IHA Yardımcı İniş Sisteminin Meta-Sezgisel Optimizasyon Yöntemleri ile Kontrolü
}

\author{
Serkan ÇAŞKA ${ }^{1}$, Ali UYSAL ${ }^{2}$ \\ Manisa Celal Bayar Üniversitesi, Hasan Ferdi Turgutlu Teknoloji Fakültesi, Makine Mühendisliği Bölümü, Turgutlu, \\ Manisa \\ Manisa Celal Bayar Üniversitesi, Hasan Ferdi Turgutlu Teknoloji Fakültesi, Mekatronik Mühendisliği Bölümü, Turgutlu, \\ Manisa
}

*Sorumlu yazar e-posta: serkan.caska@cbu.edu.tr,

ORCID ID: $h$ ttps://orcid.org/0000-0002-2157-8931

ali.uysal@cbu.edu.tr

ORCID ID: https://orcid.org/0000-0003-4850-3865

Geliş Tarihi: 01.03.2021

Kabul Tarihi: 21.10.2021

Öz
Dikey iniş/kalkış yapabilen tip insansız hava aracı(iHA) bir zemine inerken, ïHA'nın GPS hassasiyetinin düşük olması ve şasisindeki titreşim nedeniyle hedeflenen iniş noktası ile gerçek iniş noktası arasında yatay düzlemde bir miktar hata oluşur. Bu çalışmada, İHA'nın yatay düzlemde iniş yapması sırasında meydana gelen konumlandırma hatasına göre hareket eden bir sistemin kontrolü yapılmıştır. İH'nın hedef iniş noktasına göre konumunu algılamak için iki dijital kamera içeren bir stereo kamera sistemi kullanılmıştır. İHA'nın gerçek zamanlı konumu, Visual Studio'ya entegre edilmiş olan OpenCV kitaplığı kullanılarak hesaplanmıştır. Elde edilen ïA konumu, yatay düzlemde hareket edebilen bir platformun doğru akım motorları için hedef konum olarak kullanılmıştır. Sistem üzerinde yapılan denemeler kapalı mekanda ve gerçek çalışma koşullarında sağlanmıştır. İniş sistemine entegre edilmiş iki motoru kontrol eden orantı, integral ve türev(PID) tipi denetleyici katsayılarını bulmak için Genetik Algoritma(GA) ve Parçacık Sürüsü Optimizasyonu(PSO) yöntemleri kullanılmıştır. Geliştirilen denetleyicilerin performans sonuçları tablo halinde sunulmuştur.

Anahtar kelimeler

İnsansız Hava Aracl;

Parçacık sürüsü

optimizasyonu;

Genetik algoritma; PID

kontrolör

\section{Control of UAV Auxiliary Landing System with Meta-Heuristic Optimization Methods}

\begin{abstract}
While an unmanned aerial vehicle(UAV) with vertical take off and landing capability is landing onto a ground, a horizontal positioning error occurs between actual landing point and target landing point. This error occurs because of vibration on UAV chasis during flight and low GPS accuracy. In this study, control of an automatic assistive landing system that moves according to the horizontal positioning error that UAV made during its landing was carried out. A stereo camera system with two digital cameras were placed onto a moving platform that UAV lands. Cameras were used to detect actual position of the landing UAV. Real time position of landing UAV was computed by using OpenCV library added into Visual Studio. The calculated position of the landing UAV was defined as target position for two DC motors of moving platform that has horizontal motion capability. The tests of this system were performed in real and indoor conditions. Genetic algorithm (GA) and Particle Swarm Optimization(PSO) algorithm were used to calculate the coefficients of controllers that were defined as ProportionalIntegral-Derivative(PID) controllers. Developed controllers control two DC motors of the moving plate of the system. Success of the controllers were compared in table form.
\end{abstract}

Keywords

Unmanned Aerial Vehicle; Particle swarm optimization; Genetic algorithm; PID controller

C Afyon Kocatepe Üniversitesi

\section{Giriş}

Literatürde, dikey iniş kalkış yapabilen bir IHA'yı havada yakalama, yere indirme ve şarj etme konusunu ele alan birkaç çalışma bulunmaktadır
(Choi et al. 2016). Bu tür çalışmalar son 10 yılda yaygınlaşmıştır ve temel olarak iHA tabanlı ve iHA iniş platformu tabanlı yazılımsal ve donanımsal çözümler olmak üzere ikiye ayrılmıştır (Feng et al. 
2018). İHA iniş platformu tabanlı çözümler özellikle rüzgar gibi inişi zorlaştıran dış etkenlere karşı etkili bir çözüm olarak önerilmektedir ve iniş sonrası İHA bataryasının şarj edilmesi gibi süreçleri kolaylaştırmaktadır (Junaid et al. 2017). ïH'ların Maier vd. (2015) iniş yüzeyine sabitlenmiş bir seri robot manipülatör içeren bir sistem üzerinde çalışmışlardır. Böyle bir iniş sistemini model bazlı denetleyici yaklaşımları kullanarak kontrol edebilmek için öncelikle dinamik yapısının tanımlanması gerekir. Sistem tanımlama yaklaşımları, dinamik sistemlerin yapısını tanımlamak için yaygın olarak kullanılmaktadır (Wills et al. 2009).

PID denetim algoritması, mekatronik sistemleri kontrol etmek için oldukça tercih edilen geleneksel kontrol algoritmalarından biridir. Literatürde, PID ve PID tabanlı hibrit kontrolörlerle gerçekleştirilen birçok uygulama vardır (Rao et al. 2014). Kontrol uygulamalarında çoğunlukla gelişmiş kontrolörler kullanılsa da PID kontrolörler basit yapısından ve kolay uygulanabildiğinden dolayı özellikle endüstriyel alanda birçok uygulamada tercih edilmektedir (Çınar vd. 2019). Bununla birlikte PID parametrelerinin deneme yanılma yöntemiyle ayarlanması zaman kaybına sebep olmaktadır. Ayrıca parametreleri deneme yanılma yöntemiyle belirlenen kontrolörler optimal bir çalışma karakteristiği sunmamaktadır.

PID denetleyicilerin katsayılarının tahmin edilmesi, optimal kontrol konsepti altında tanımlanabilir (Nezhadhosein et al. 2015). Son yıllarda yapay zeka temelli optimal kontrol yaklaşımları birçok çalışmada kullanılmaktadır (Modares and Sistani 2011). Denetleyicilerin yapısını tahmin etmek için özellikle meta-sezgisel algoritmalar tercih edilmektedir (Abo-Hammour et al. 2011).

Genetik algoritmalar, temel meta-sezgisel optimizasyon algoritmalarından biridir ve literatürde birçok kontrol sisteminin yapısını belirlemek için kullanılmıştır (Jayachitra and Vinodha 2014). Genetik algoritmalar yönteminin kontrol uygulamalarında tercih edilmesinin başlıca sebebi yapısının basit ve kontrol alanında uzun yıllardır başarıyla kullanılıyor olmasıdır. Kontrol uygulamalarında başarıyla kullanılan bir diğer algoritma da PSO'dur. PSO algoritması birçok dinamik sistemin modellenmesinde ve bu sistemlere kontrolör tasarlanmasında kullanılmıştır (Mukhtar et al. 2019).

Bu çalışmada, dikey iniş kalkış yapabilen IHA'lar için bir yardımcı iniş platformunun tasarımı ve optimum kontrolü sunulmuştur. Hedef iHA'nın konumunu izlemek için bir stereo kamera sistemi kullanılmıştır. iHA'nın gerçek zamanlı konumu, Visual Studio ortamında OpenCV kütüphanesi kullanılarak elde edilmiştir. ïA'nın konum bilgisi, iki eksende yatay hareket yapabilen bir platform için hedef konum olarak tanımlanmıştır. Platformun iki ekseninin hareketini temsil eden dinamik modeller Matlab yazılımının Sistem Tanımlama Araç Kutusu kullanılarak elde edilmiştir. Genetik algoritma (GA) ve Parçacık sürüsü optimizasyonu (PSO) algoritması, platformun iki fırçalı DC motoru için geliştirilen PID denetleyicilerin katsayılarını bulmak için kullanılmıştır. Platformun hareketi, Waijung Blockset üzerinden Matlab - Simulink yazılımına bağlanan STM32F4 mikrodenetleyici aracilığıyla gerçek çalışma koşullarında ve kapalı mekanda sağlanmıştır.

\section{Materyal ve Metot}

\section{1 iniş sisteminin çalışma prensibi}

Bu çalışma kapsamında tasarlanan ve kontrol edilen platform, dikey iniş kalkış yapabilen tip bir IHA'nın hareketlerine göre yatay düzlemde hareket edebilmektedir. Lineer mekanizmaların $X$ ve $Y$ ekseninde hareketini sağlamak için $24 \mathrm{~V}$ çalışma voltajına ve $250 \mathrm{~W}$ güce sahip iki adet fırçalı DC motor kullanılmıştır. IHA, kumanda kullanılarak manuel olarak platforma yönlendirilmiştir. Tasarlanan sistemin genel görünümü Şekil 1'deki gibidir. 


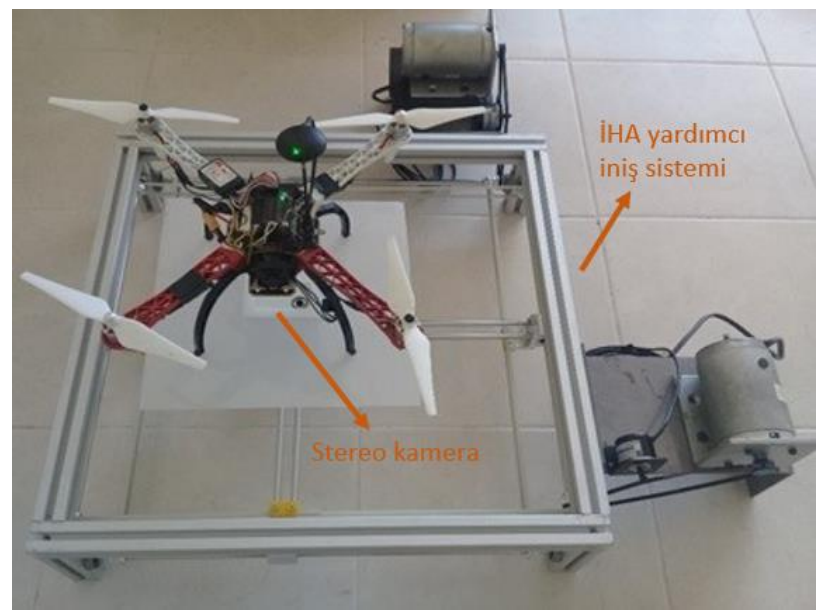

Şekil 1. İHA iniş sistem sisteminin genel görünümü
Bu çalışmada, stereo görüş sistemi olarak iki adet dijital kamera kullanılmış ve hedef iHA'nın yatay hareketini tespit etmek için taşıyıcı plaka üzerine yerleştirilmiştir. Stereo kamera gerçek zamanlı görsel verileri bir bilgisayara aktarmaktadır. IHA'nın konumu Simulink ortamında çalışan Waijung blok seti aracılığıla mikrodenetleyiciye gönderilmektedir. Platformun taşıyıcı plakasının gerçek zamanlı konum verilerini tespit etmek için enkoder kullanılmıştır. Simulink'te kurulan kontrol yapısı Şekil 2'de verilmektedir.

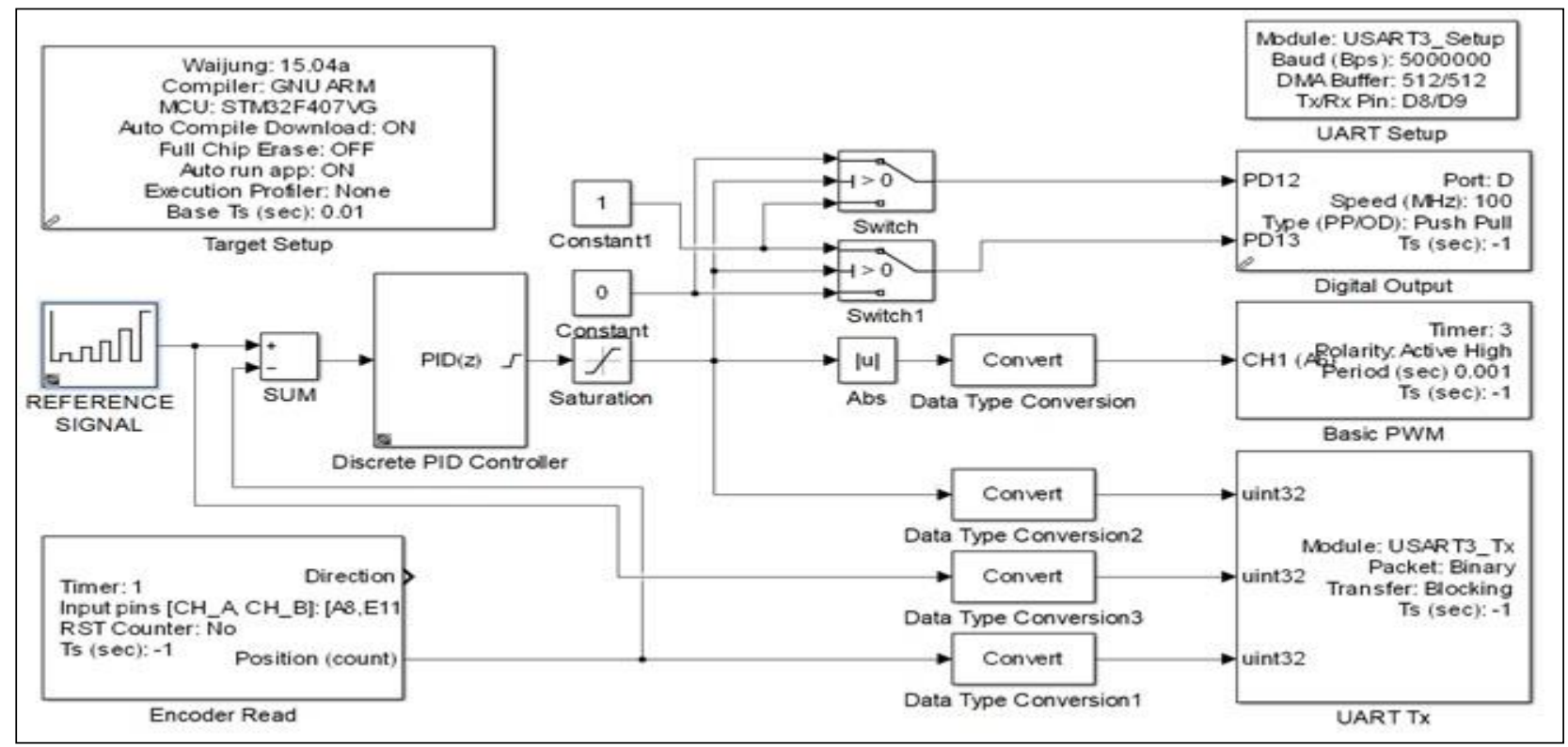

Şekil 2. Simulink kontrol blokları

DC motorları hedef konum verilerine göre kontrol etmek için STM32f4 tipi mikro denetleyici kullanılmıştır. Geliştirilen sistemin veri akışı çerçevesi Şekil 3'te verilmiştir.

\subsection{Sistem modelleme ve kontrolör tasarımı}

Bir sistem için kontrolörler geliştirmeden önce, sistemin dinamik davranışı matematiksel bir model olarak tanımlanmalıdır. Matlab'ın sistem tanımlama araç kutusu, literatürdeki birçok uygulamada sistemlerin modelini tanımlamak için başarıyla kullanılmıştır.

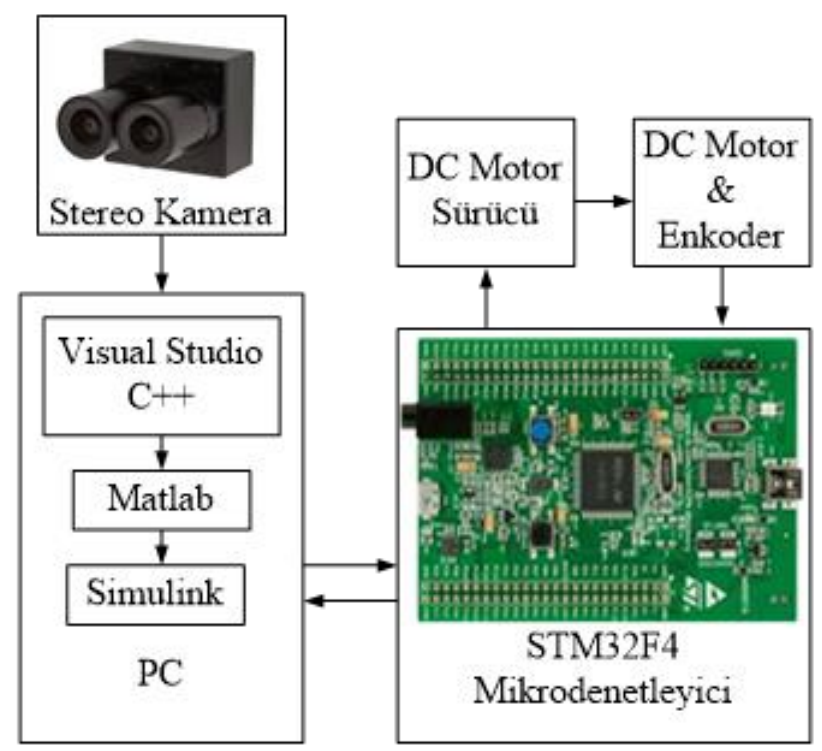

Şekil 3. Sistem bileşenleri arasındaki veri akışı 
Bu çalışmada, iHA iniş platformunun iki eksenine ait ayrık zamanlı z-domeni modellerini elde etmek için Matlab Sistem Tanımlama Araç Kutusu kullanılmıştır. Şekil 4 'te verilen zaman bölgesinde tanımlı giriş sinyali, iHA iniş sisteminin iki eksenini kontrol eden fırçalı DC motor sürücülerine uygulanmıştır.

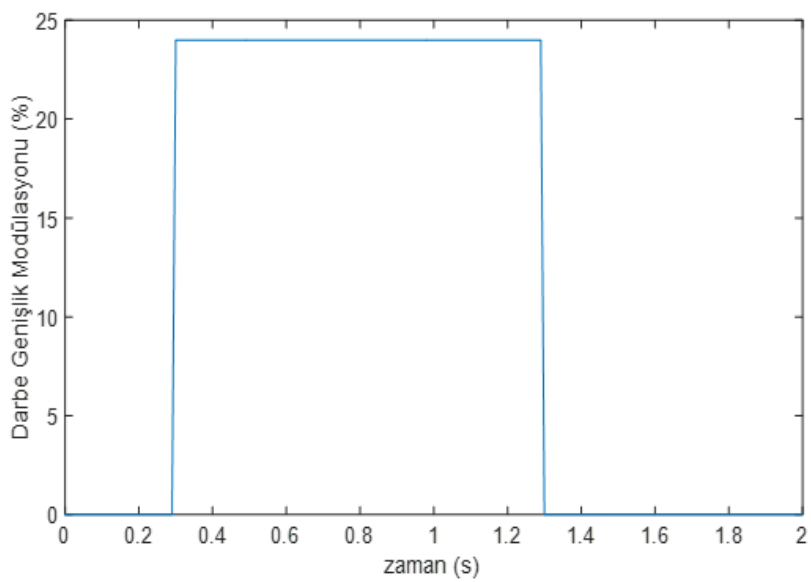

Şekil 4. Motor sürücülerine uygulanan zaman bölgesine ait giriş işareti

Waijung blok seti, DC motor sürücülerine giriş verilerini göndermek ve sistemin $\mathrm{X}$ ve $\mathrm{Y}$ eksenindeki doğrusal mekanizmaların çıkış verilerini almak için kullanılmıştır. Platformun X ekseni için 0.998 R-kare değeri ve $Y$ ekseni için 0.997 R-kare değeri ile iki dinamik model elde edilmiştir. $X$ ve $Y$ ekseninin dinamik modelleri Denklem 1 ve Denklem 2'de verilmiştir.

$$
\begin{aligned}
& 0.3454 z^{2}=z^{2}-1.9677 z+0.9677 \\
& 0.3459 z^{2}=z^{2}-1.9680 z+0.9680
\end{aligned}
$$

\subsection{GA yönteminin yapısı, çalışma prensibi ve akış diyagramı}

Bu çalışmada, platformun iki eksenine takılmış DC motorları kontrol eden optimal PID katsayılarını elde etmek için GA yöntemi kullanılmıştır. GA prosedürü, kromozom popülasyonunun oluşturulmasıyla başlamaktadır. Kromozomlar, aday çözümleri temsil etmektedir ve başlangıçta rastgele seçilmektedir. Kromozomlar, genler olarak adlandırılan bitlerden oluşturulur. GA prosedüründe, kromozomların mutasyonunu gerçekleştirmek için mutasyon operatörü kullanılırken, doğal çoğalmayı sağlamak için çaprazlama operatör kullanılmaktadır.
Oluşturulan kromozomlardan uygunluk değeri daha iyi olanlarının optimizasyon sürecine katkısını artırmak için kromozomlara seçim işlemi uygulanır. $\mathrm{Bu}$ çalışmada, GA prosedüründe tek noktalı çaprazlama, elitist seçim ve \%10 mutasyon oranı kullanılmıştır. GA optimizasyon sürecinin akış diyagramı Şekil 5 'te gösterilmiştir.

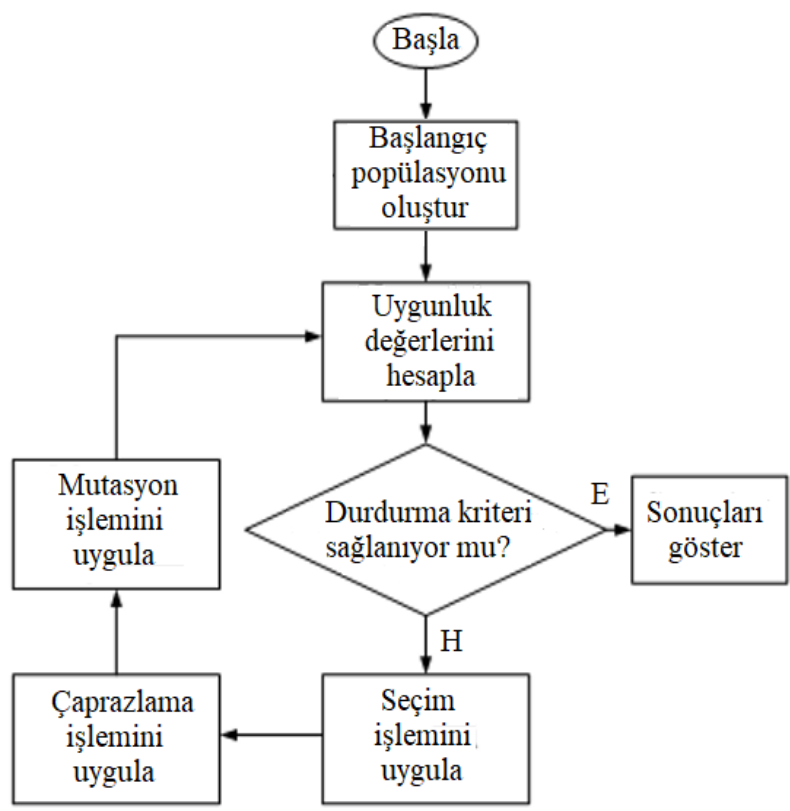

Şekil 5. GA yöntemine ait akış diyagramı

\subsection{PSO yönteminin yapısı, çalışma prensibi ve akış diyagramı}

Bu çalışmada, GA yönteminin yanında meta-sezgisel algoritmalardan olan PSO algoritması da geliştirilen sistem üzerindeki motorların kontrolörlerinin tasarlanmasında kullanılmıştır. PSO algoritması, kuş ve balık sürülerinin sosyal davranışları dikkate alınarak 1995 yılında geliştirilmiştir. Bu algoritmanın çalışma mantığı balık ve kuş sürülerinin yiyecek veya yuva bulmak için bir alanı incelemesine dayalıdır. PSO algoritmasında kullanılan sürü içerisindeki her bir elemana parçacık denir. PSO'ya ait işlemlerden oluşan akış diyagramı şekil 6 'da verilmiştir. Bu çalışma kapsamında PSO algoritmasında kullanılan parametreler Çizelge 1'de görüldüğü gibidir. 


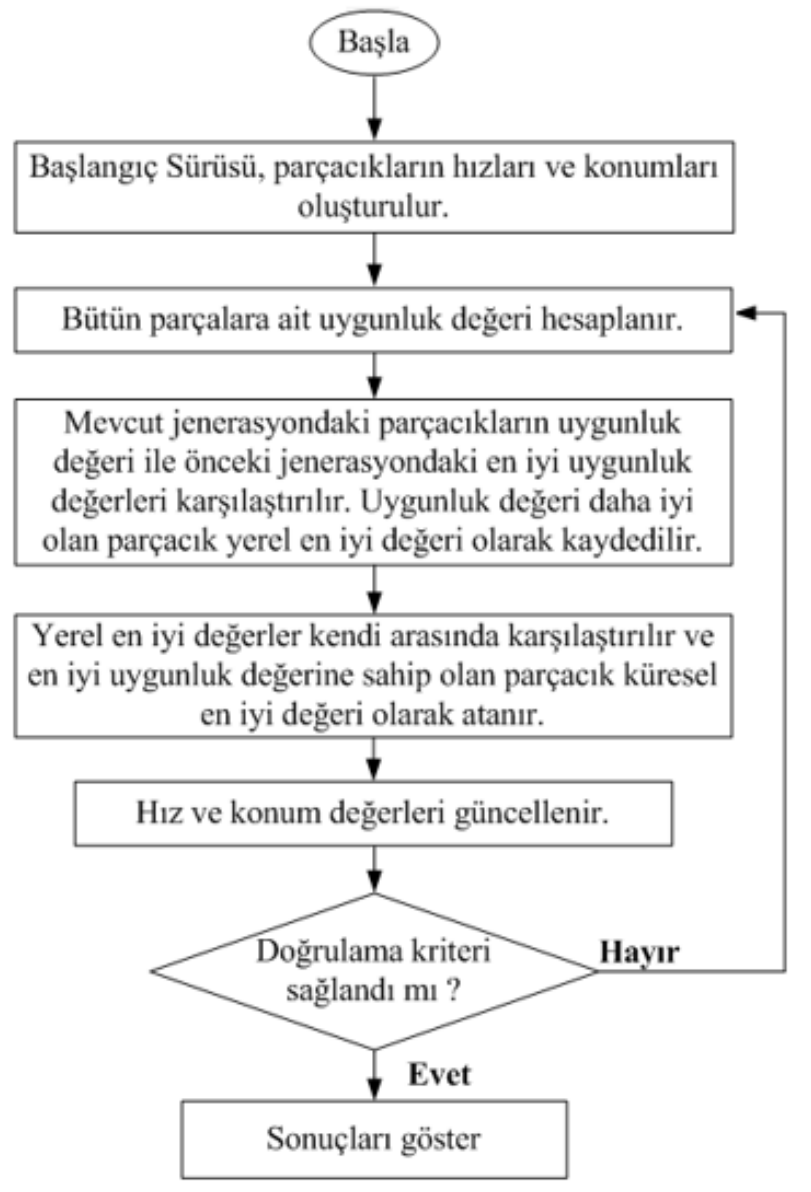

Şekil 6. PSO yöntemine ait akış diyagramı

Çizelge 1. PSO yöntemine ait parametreler

\begin{tabular}{lc}
\hline $\begin{array}{l}\text { Parametre } \\
\text { ismi }\end{array}$ & Parametre değeri \\
\hline $\begin{array}{l}\text { Sürü } \\
\text { büyüklüğü }\end{array}$ & 30 \\
\hline $\begin{array}{l}\text { Hılanma } \\
\text { katsayıları }\end{array}$ & 1 \\
\hline $\begin{array}{l}\text { Eylemsizlik } \\
\text { momenti }\end{array}$ & 0.9 \\
\hline
\end{tabular}

Bir optimizasyon prosedüründeki her yinelemede bulunan çözümün uygunluğunu hesaplamak için kullanılan fonksiyona uygunluk fonksiyonu denir. Bu çalışmadaki optimizasyon sürecinin uygunluk fonksiyonunu elde etmek için referans sinyal ile sistemin tepkisi arasında oluşan hata dikkate alınmıştır ve literatürde IAE olarak geçen mutlak hatanın integrali ve $\mathrm{MO}$ (maksimum aşma) değerleri kullanılmıştır (Kealy and O'Dwyer 2003). Hem GA hem de PSO iletiminde, PID kontrolör parametreleri olan $\mathrm{Kp}, \mathrm{Ki}$ ve $\mathrm{Kd}\left[\begin{array}{ll}0 & 5\end{array}\right]$ aralığında aranmıştır.
Uygunluk fonksiyonunun formülasyonu Denklem 3 'te verildiği gibidir.

$$
U F=I A E+0.1 * M O
$$

\subsection{Görüntü işleme ve OpenCV}

Bu çalışmada hedef iHA'nın tespiti için iki dijital kameradan oluşan bir stereo kamera sistemi kullanılmıştır. Her iki kamera da 640x480 piksel çözünürlüğe ve $10 \mathrm{~mm}$ odak uzunluğuna sahiptir. IHA'nın stereo kameralarla algılanmasını sağlamak için iHA'nın altına Şekil 7'de gösterilen kırmızı bir işaret yerleştirilmiştir.

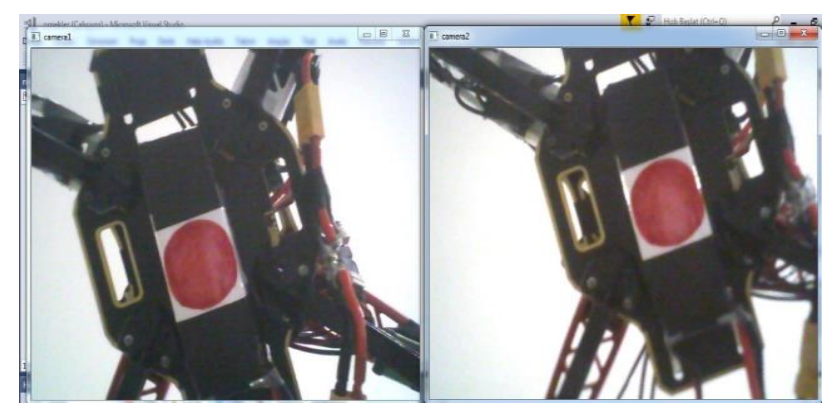

Şekil 7. IHA'nın altına yerleştirilmiş işaret

Stereo kameralar, taşıyıcı plakanın ortasında yerleştirilmiştir. iHA ile hareket ettirici plakanın merkezi arasındaki yatay mesafe geometrik bir hesapla elde edilmiştir. Hedef iHA'nın konumunu veren formül üçgen benzerliği kullanılarak elde edilmiştir. Şekil 8'de stereo kamera sisteminin yapısı verilmiştir.

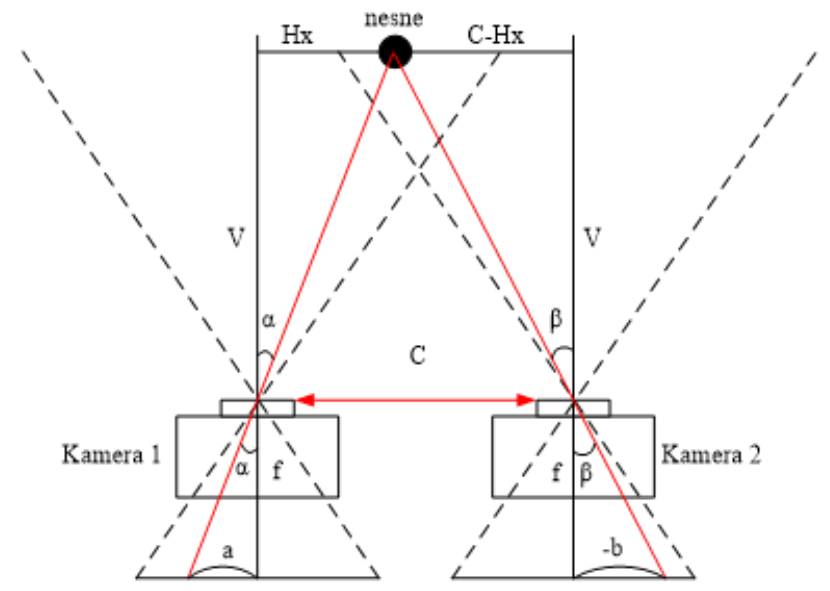

Şekil 8. Stereo kamera sistemi şeması 
IHA ile hareket ettirici plaka merkezi arasındaki dikey ve yatay mesafelerin hesaplanmasında kullanılan parametrelerden C iki kamera lensi arasındaki mesafeyi, $f$ kameraların odak uzunluğunu, a sol kamera tarafından çekilen dijital görüntünün sol kameranın merkezine olan uzaklığını, b sağ kamera tarafından çekilen dijital görüntünün sağ kameranın merkezine olan uzaklığını, V ïH'nın kameralara dik mesafesini, $\mathrm{Hx}$ Kamera 1'in merkezi ile hedef iHA arasındaki yatay mesafeyi ifade etmektedir. Şekil 8 üzerinden elde edilen büyüklükler ve geometri bilgisi kullanılarak Denklem 4 ve Denklem 5 elde edilmiştir.

$\frac{a}{H x}=\frac{f}{V}$ ve $V=f *\left(\frac{H x}{a}\right)$

$\frac{-b}{(C-H x)}=\frac{f}{V}$ ve $V=f *((C-H x) /-b)$

Denklem 4 ve Denklem 5 'teki $\vee$ değerlerini eşitleyerek, Kamera 1 'in merkezi ile hedef iHA arasındaki yatay mesafe Denklem $6^{\prime}$ daki gibi hesaplanır:

$H x=C * \frac{a}{a-b}$

Hy, Kamera 1'in merkezi ile hedef iHA arasındaki y eksenindeki yatay mesafedir. $\mathrm{Hy}$ de $\mathrm{Hx}$ hesaplamasında kullanılan geometrik yaklaşımla hesaplanmıştır. Kamera 1 veya kamera 2'nin merkezi ile hedef iHA arasındaki dikey mesafeyi ifade eden $\mathrm{V}$ değeri $\mathrm{Hx}$ elde edildikten sonra hesaplanmıştır.

Stereo kamera sisteminden gelen görüntüdeki iHA üzerine yerleştirilen kırmızı renkli işaretin konumunu tespit etmek için Visual Studio ortamında, C++ ile yazıımış ve OpenCV kütüphanesi tarafından desteklenen bir yazılım kullanılmıştır. Yazılım, HSV (Ton, Doygunluk, Değer) filtresini kullanarak iHA üzerindeki işaretin konumunu tespit etmektedir. Kırmızı renkli işareti algılamak için HSV değer aralıkları H için 40-179, S için 229-255, V için 92-164 olarak seçilmiştir.

\section{Bulgular}

Simulink ortamında GA ve PSO tabanlı kontrolörler Denklem 1 ve Denklem 2'de verilen dinamik modeller dikkate alınarak tasarlanmıştır. $X$ ekseninde kontrolör parametreleri GA tabanlı PID kontrolör için $\mathrm{Kp}=1.893, \mathrm{Ki}=1.656, \mathrm{Kd}=0.087$ olarak hesaplanmıştır. PSO tabanlı PID denetleyicisi için $\mathrm{Kp}=0.981, \mathrm{Ki}=0.040, \mathrm{Kd}=0.281$ olarak hesaplanmıştır. Şekil 9'da, GA yöntemi ve PSO yöntemi ile elde edilen kontrolörlerin $X$ eksenindeki performansı gösterilmiştir.

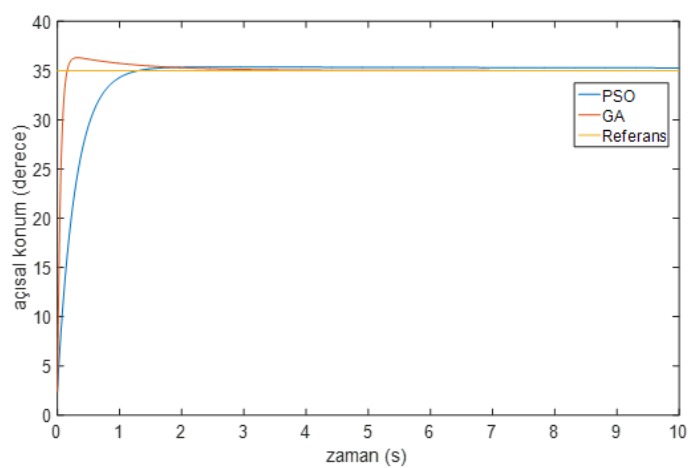

Şekil 9. Geliştirilen kontrolörlerin X eksenini kontrol eden motorun konum kontrolü üzerindeki başarısı

$Y$ ekseninde ise GA tabanlı PID kontrolör için kontrolör parametreleri $\mathrm{Kp}=1.073, \mathrm{Ki}=0.076, \mathrm{Kd}=$ 0.014 ve PSO tabanlı PID kontrolör için $\mathrm{Kp}=0.935$, $\mathrm{Ki}=0.011, \mathrm{Kd}=0.190$ olarak hesaplanmıştır. Şekil 10 'da, GA yöntemi ve PSO yöntemi ile elde edilen kontrolörlerin $Y$ eksenindeki performansı gösterilmiştir.

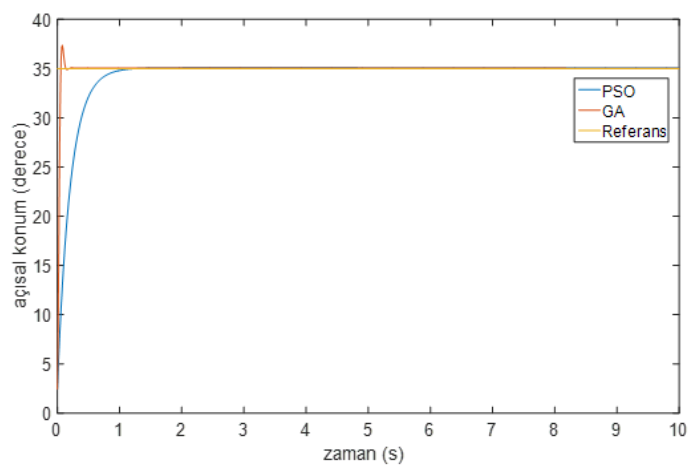

Şekil 10. Geliştirilen kontrolörlerin Y eksenini kontrol eden motorun konum kontrolü üzerindeki başarısı 
Çizelge 2'de, geliştirilen kontrolörlerin başarısının ayrıntıları verilmiştir. Çizelge 2 'de yer alan Tr (yükselme zamanı), Tp (tepe zamanı), Mp (tepe zamanındaki maksimum aşma), Ts (sürekli durum zamanı), Ess (sürekli durum hatası) gibi parametreler denetleyicilerin başarısına karar vermek için kullanılmıştır.

Çizelge 2. Geliştirilen kontrolörlere ait performans değerleri

\begin{tabular}{llcc}
\hline Eksen ismi & $\begin{array}{l}\text { Performans } \\
\text { kriteri }\end{array}$ & PID-GA & PID-PSO \\
\hline \multirow{3}{*}{$\mathrm{Tr}(\mathrm{s})$} & 0.17 & 1.24 \\
$\mathrm{Tp}(\mathrm{s})$ & 0.31 & 1.82 \\
& $\mathrm{Mp}(\%)$ & 4.14 & 2.42 \\
& $\mathrm{Ts}(\mathrm{s})$ & 4.11 & 4.52 \\
$\mathrm{Ess}(\%)$ & 0.01 & 0.97 \\
\hline & $\operatorname{Tr}(\mathrm{s})$ & 0.03 & 1.19 \\
$\mathrm{Tp}(\mathrm{s})$ & 0.07 & 1.65 \\
& $\mathrm{Mp}(\%)$ & 7.03 & 0.03 \\
& $\mathrm{Ts}(\mathrm{s})$ & 0.56 & 1.97 \\
\hline
\end{tabular}

Çizelge 1'de, geliştirilen kontrolörlerin sistemin X ve $Y$ eksenlerindeki hareketi üzerindeki başarısı incelendiğinde GA tabanlı kontrolörün $\mathrm{Tr}$, Tp süre kriterlerinde ve Ess sürekli durum hatası kriterinde PSO tabanlı denetleyiciye göre daha başarılı olduğu görülmektedir.

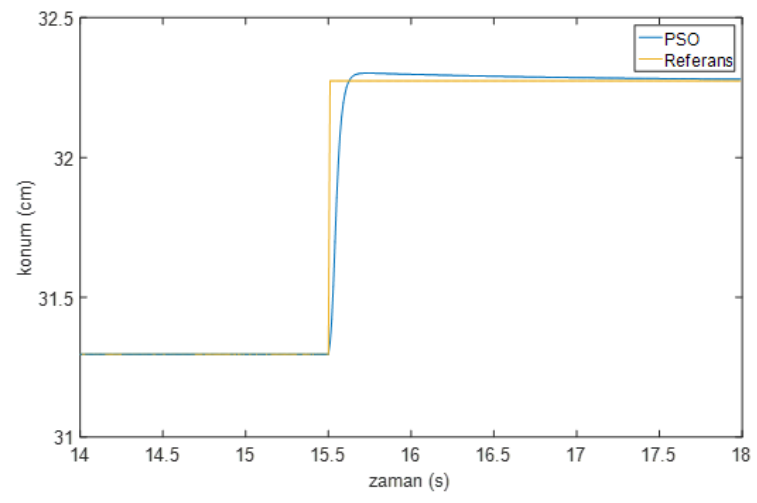

Şekil 11. PSO tabanlı kontrolörün kullanılması durumunda sistemin $\mathrm{X}$ eksenindeki hareketi

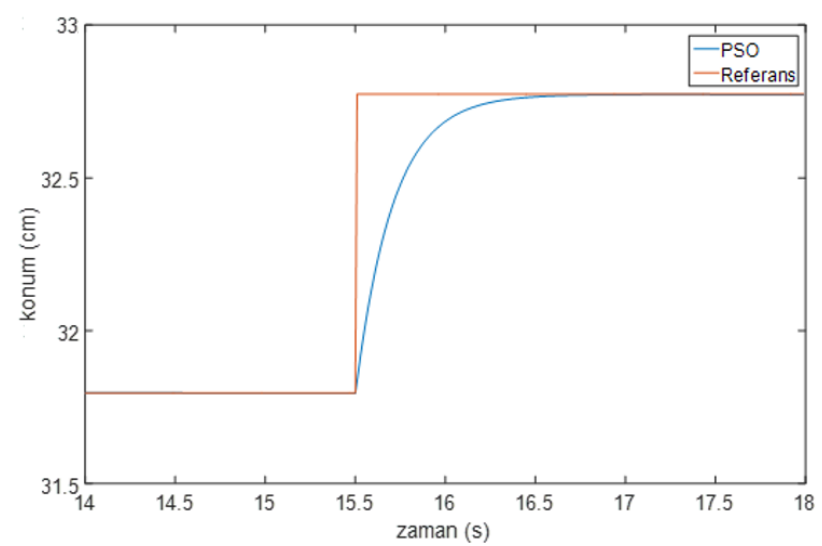

Şekil 12. PSO tabanlı kontrolörün kullanılması durumunda sistemin Y eksenindeki hareketi

Bununla birlikte PSO tabanlı kontrolör Ts ve Mp kriterlerinde GA tabanlı kontrolöre göre daha başarılıdır. Ts ve $M p$ kriterlerinde daha başarılı olması sebebiyle ve ayrıca Tr, Tp ve Ess kriterlerinde kabul edilebilir seviyede başarı sergilemesi sebebiyle PSO tabanlı kontrolör sistemin $X$ ve $Y$ eksenlerindeki hareketinin gerçek çalışma şartlarındaki uygulamalarında kullanılmak üzere tercih edilmiştir. Kontrolör yapıları tespit edildikten sonra IHA iniş uygulaması gerçek koşullarda gerçekleştirilmiştir. Şekil 11 ve Şekil 12 sırasıyla $X$ ve $Y$ ekseni hareketi için tasarlanmış PSO tabanlı kontrolörlerin performansını göstermektedir.

\section{Tartışma ve Gelecek Çalışması}

$\mathrm{Bu}$ çalışma, bir IHA iniş sisteminin kontrolör parametrelerini GA ve PSO optimizasyon yöntemlerini kullanarak tanımlamanın mümkün olduğunu göstermiştir. Bununla birlikte, PSO ile hesaplanan kontrolör parametreleri, GA ile elde edilen parametrelerden daha iyi dinamik davranış sağlamıştır. Şekil 11 ve Şekil 12 incelendiğinde sistemin $X$ ve $Y$ eksenlerindeki dinamik davranışının farklı olduğu görülmektedir. Bu durum, bu iki eksende hareket için kullanılan motorlar her ne kadar özdeş olsa da diğer hareket etkenleri olan kayış gerginliği ve özellikle sürtünmenin farklı olmasından kaynaklanmaktadır.

iHA'nın platforma ilk teması sırasında kayma ve titreşim meydana gelmiş ve bu da iHA'nın hareket ettirici plakanın tam ortasına inmesini engellemiştir. Daha iyi iniş koşulları sağlamak için geliştirilen 
sistemin mevcut haline bir IHA sabitleme parçasının eklenmesi gerektiği açıktır. Bu çalışmada, iHA'ların inişinde oluşan konum hatasını gideren ve emniyetli inişini sağlayan 2 serbestlik dereceli yardımcı bir sistem tasarlanmış ve kontrol edilmiştir. Geliştirilen sistem düz zeminde kullanılabilir. Bundan sonraki çalışmalarda eğimli zeminde bile güvenli bir iniş sağlamak için, geliştirilen iniş sistemi yapısına Stewart platformu gibi 6 serbestlik dereceli bir paralel manipülatörü entegre edilebilir.

\section{Kaynaklar}

Abo-Hammour, Z. S., Asasfeh, A. G., Al-Smadi, A. M. and Alsmadi, O. M., 2011. A novel continuous genetic algorithm for the solution of optimal control problems, Optimal Control Applications\&Methods, 32(4), 414-432

Çınar S. M., Balcı Z. and Yabanova İ., 2019. Performing Speed Control of a DC Motor with Auto-Tuning PID, Afyon Kocatepe Üniversitesi Fen ve Mühendislik Bilimleri Dergisi, 19, 690-696

Choi, C.H., Jang, H.J., Lim, S.G., Lim, H.C., Cho, S.H., Gaponov, I., 2016. Automatic wireless drone charging station creating essential environment for continuous drone operation. In Proceedings of the 2016 International Conference on Control, Automation and Information Sciences, ICCAIS 2016, Ansan, South Korea, 27-29 October,

Feng, Y., Zhang, C., Baek, S., Rawashdeh, S. And Mohammadi, A., 2018. Autonomous Landing of a UAV on a Moving Platform Using Model Predictive Control, Drones, 2(4), 34.

Jayachitra, A. and Vinodha, R., 2014. Genetic Algorithm Based PID Controller Tuning Approach for Continuous Stirred Tank Reactor, Advances in Artificial Intelligence, 2014,1-8.

Junaid, A.B., Konoiko, A., Zweiri, Y., Sahinkaya, M.N., and Seneviratne, L. 2017. Autonomous wireless selfcharging for multi-rotor unmanned aerial vehicles, Energies, 10(6), 803.

Kealy,T. and O'Dwyer, A., 2003. Analytical ISE Calculation And Optimum Control System Design. Proceedings of the Irish Signals and Systems Conference, Limerick, Ireland, July, 418-423.
Maier, M., Oeschger, A. and Kondak, K., 2015. Robotassisted Landing of VTOL UAVs: Design and Comparison of Coupled and Decoupling Linear State-space Control Approaches. IEEE Robotics and Automation Letters, 1(1), 114-121.

Modares, H. and Naghibi-Sistani, M.-B., 2011. Solving nonlinear optimal control problems using a hybrid IPSO-SQP algorithm, Engineering Applications of Artificial Intelligence, 24(3), 476-484

Mukhtar, A., Tayal, V. K. and Singh, H., 2019. PSO Optimized PID Controller Design for the Process Liquid Level Control, 3rd International Conference on Recent Developments in Control, Automation \& Power Engineering (RDCAPE), Noida, India, 10-11 October, 590-593.

Nezhadhosein, S., Heydari, A. and Ghanbari R., 2015. A Modified Hybrid Genetic Algorithm for Solving Nonlinear Optimal Control Problems, Mathematical Problems in Engineering, 2015, 1-21

Rao, P. V. G. K., Subramanyam, M. V. and Satyaprasad, K., 2014. Study on PID Controller Design and Performance Based on Tuning Techniques, International Conference on Control, Instrumentation, Communication and Computational Technologies (ICCICCT), Kanyakumari, India, 10-11 July, 1411-1417

Wills, A., Mills, A. and Ninness, B., 2009. A MATLAB Software Environment for System Identification?. Proceedings of the 15th IFAC Symposium on System Identification, Saint-Malo, France, 6-8 July, 741-746. 